\title{
Droop control technique for equal power sharing in islanded microgrid
}

\author{
A. W. N. Husna ${ }^{1}$, M. A. Roslan ${ }^{2}$, M. H. Mat ${ }^{3}$ \\ ${ }^{1}$ Centre of Excellent for Renewable Energy, School of Electrical Systems Engineering, \\ Universiti Malaysia Perlis, Malaysia \\ ${ }^{2}$ School of Electrical Systems Engineering, Universiti Malaysia Perlis, Malaysia \\ ${ }^{3}$ Centre for Diploma Studies, Universiti Malaysia Perlis, Malaysia
}

\begin{tabular}{l} 
Article Info \\
\hline Article history: \\
Received Sep 17, 2018 \\
Revised Nov 29, 2018 \\
Accepted Dec 14, 2018 \\
\hline Keywords: \\
Fuzzy control \\
Robust droop \\
Islanded microgrid \\
Parallel-connected inverters \\
Proportional load sharing \\
Frequency regulation \\
Reduction block
\end{tabular}

Corresponding Author:

A.W.N. Husna, Centre of Excellent for Renewable Energy,

School of Electrical Systems Engineering, Universiti Malaysia Perlis, Pauh Putra Campus, 02600 Arau, Perlis, Malaysia.

Email: nurulhusna.awb@gmail.com

\begin{abstract}
This paper presents a droop control technique for equal power sharing in islanded microgrid. In this study, the proposed controller is based on the frequency droop method, is applied to a robust droop controller in parallel connected inverters. The previous robust droop controller deals with voltage droop method. A modification has been formed against this controller by adding a fuzzy logic controller with the frequency droop method. The only sharing error which is concentrated in this paper is the error in sharing the rated frequency among the inverters. By adapting fuzzy in the robust droop, it tries to eliminate the frequency error, hence that the frequency reference of the inverters keeps maintain at $50 \mathrm{~Hz}$. A derivation of generalized models of a single-phase parallel-connected inverter system is shown. The simulation results show that the proposed controller with FLC is able to improve the stability of frequency reference and the performance of power sharing between the inverters under the inductive line impedance.
\end{abstract}

Copyright (C) 2019 Institute of Advanced Engineering and Science. All rights reserved.

\section{INTRODUCTION}

Advanced development of distributed generation (DG) units in many countries nowadays has attracted most researchers in all over the world due to the availability of different energy resources such as photovoltaic panels, fuel cells, and wind turbines [1]. Through the concept of a microgrid which is the best option to reduce a dependency on the local utility, consists of at least one DG, energy storage devices and associated loads. Microgrid with two mode operations either in grid connected or islanded; has been considered as one of the nominess to support smooth installation of DGs as the installation of many DGs itself could be harmful to the power quality of utility power systems [2]-[4]. A details correlation between microgrid and DG already discovered by Ping et al [5]. Basically, microgrid control in an islanded mode is more complex than grid connected mode. The voltage and frequency of the microgrid are supported by the main grid if in the grid connected mode. In contrast, the voltage and frequency control and even power management process will be generated by DG units in islanded mode. The occurrence of power mismatch between the DG and the load will lead to the unbalanced allowed value of the load voltage and frequency deviation as well as unstable behaviours especially the existence of circulating current. Thus, it is necessary to have a good controller to support voltage and frequency stability as well as suitable power sharing among DG units in islanded mode operation [6]. 
The essential objective of an islanded mode is to keep up precise power sharing among various DG. Whenever the operation of microgrid shifted to island mode, electric potential, $E$ and frequency, $\omega$ are considered to be maintained with several inverters working in parallel and sharing the load. These inverters act in regulating the voltage; amplitude and frequency, instead of different mode of operation like other converter [7]; besides providing the required current needed. However, the issue of power quality [8] that contributed by the existence of transient circulating current in line impedance [9] will lead to the system instability, thus can harmful the inverters [10] due to mismatch of the output voltage. In an islanded microgrid, loads must be properly shared by multiple DG units. Generally, the control techniques for parallel operation of inverters in islanded microgrid operation can be split into two categories; droop control techniques[11], [12] and active load sharing techniques [13], [14].

Droop control is the common control that widely used in microgrid due to no dependenment on communication among parallel-connected inverters thus making it highly modular and reliable [15]-[17]. It is applicable when two or more inverters are applied. Generally, it detects the output power as a feedback parameter while the deviation of DC voltage is controlled in proportion to the output power. Typically, the voltage droop control results in poor reactive power sharing whilst the frequency droop control always achieves accurate real power sharing. It is due to the different offsets of local loads as well as the mismatch in feeder impedances.

This paper seeks to expand the method of robust droop presented in [18] by adapted with frequency control instead of the voltage control using fuzzy logic control (FLC). It will retain the frequency reference of $50 \mathrm{~Hz}$ in parallel-connected inverters using inductive line impedance. The control approach presented by the previous author applied $\mathrm{Q}-\omega$ and $\mathrm{P}-E$ droop to the resistive line impedance with switching action of pulsewidth modulation (PWM) to improve the strategy that works for grid-connected applications via adding a unit to regulate the load voltage. In this work, an FLC is adjusted to the robust control by putting through the frequency droop precisely integrated in $\mathrm{Q}-\omega$. Practically, the operation of the controller is robust against load perturbation and even an emergency circumstance such as disconnection of DG unit and the proposed controller is actually being designed for frequency control indeed. The parallel-connected inverters incorporate with a proportional-resonant controller (PR) and sinusoidal pulse-width modulation (SPWM) instead of proportional-integral (PI) and PWM in the islanded microgrid. Various simulations have been taken out to verify and analysis the capability of the proposed controller against the robust droop controller.

\section{SYSTEM CONFIGURATION OF PARALLEL-CONNECTED INVERTER}

In this section will explain in details of construction of single-phase full-bridge inverter and the parallel-connected inverters used in the simulation.

\subsection{Model of single-phase inverter}

The single-phase inverter is an electronic circuit that enables a voltage to be applied across a load in either direction. It can be simplified justified with a switching scheme of full-bridge converter. Typically, it consists of a DC power source, and a bridge-type inverter with $L C L$ filter as shown in Figure 1. The inverter is a device which converts a DC input supply voltage into symmetrical AC voltage based on the modulation signal from the SPWM modulation. The inductance, resistance, and capacitance are represented by $L_{f}, R_{f}$, and $C_{f}$. The line impedance represented $R_{\text {line }}$ and $L_{\text {line }}$ between the inverter and the load is the equivalent impedance due to connecting lines or cables.

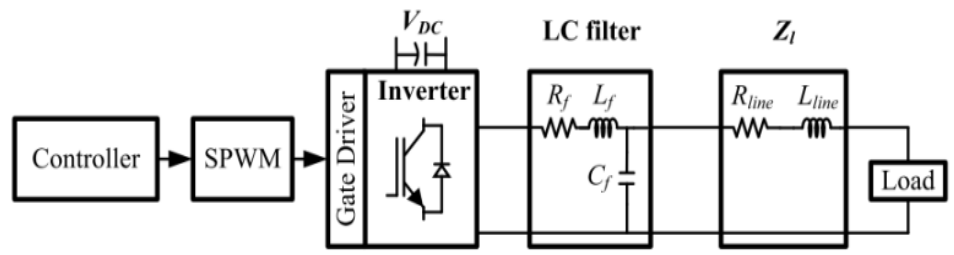

Figure 1. Block diagram of an inverter

\subsection{Parallel-connected inverter}

Three parallel-connected inverters are used to fill in the microgrid configuration as depicted in Figure 2. The model of parallel-connected inverters is a necessary in order to apply droop method in the system. Previously, a conventional PI controller is used with the voltage feedback loop [13] to regulate the 
ouput voltage. Therefore, it is sensible to used PR controller instead of PI controller due to its superior performance in terms of less steady-state error, good dynamic response, as well as its capability in reducing steady-state deviation of frequency and amplitude [19]. In order to ensure in-phase similarity of the output voltage of each inverter, the same voltage reference is used, $V \angle 0^{\circ}$. PR controller gain the feedback values of output voltage and current from the inverter, thus, generate a proper controlled signal before transmitted to SPWM. Then, SPWM used to put through the switching process and pass a practical condition of the microgrid. The active and reactive power of each inverter is obtained based on the voltage and current measurement after filtering, later will be fed to the proposed controller block to produce new value of reference voltage, $\mathrm{V}_{\text {ref }}$ and angular frequency, $\omega_{i}$ which will be led to proportional power sharing.

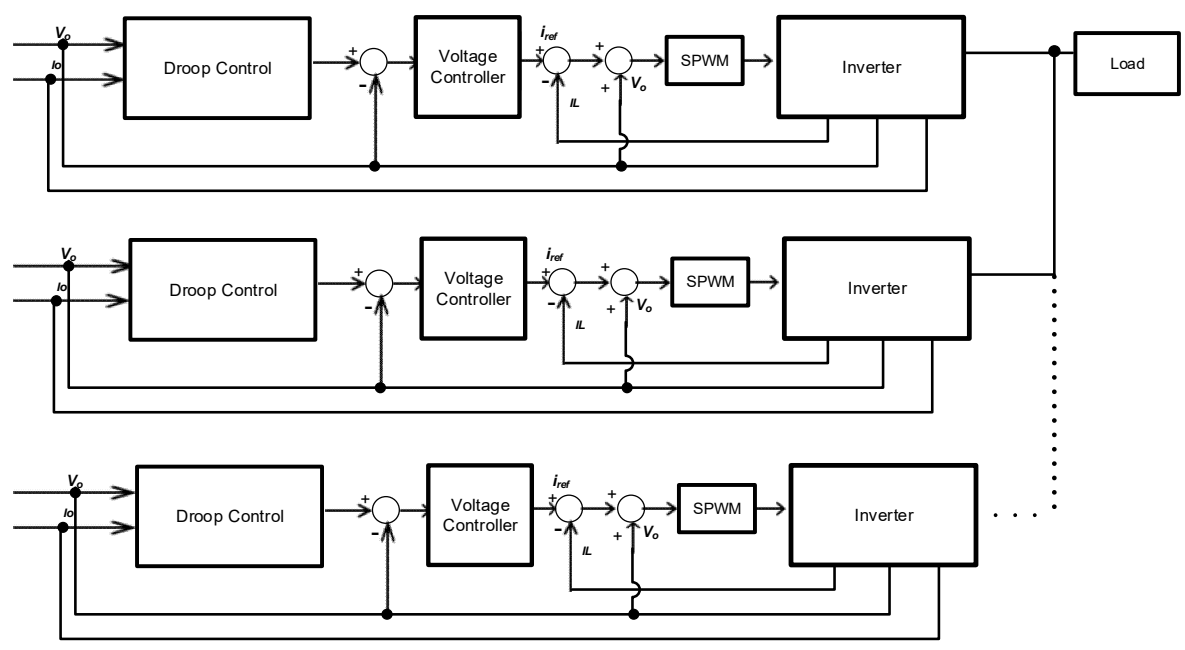

Figure 2. Parallel-connected inverters in microgrid configuration

\section{CONTROL SCHEME}

\subsection{Robust droop control}

As presented in [18], the quantitative analysis of the error in power sharing has been carried out by the author. From the paper, the sharing error which is from the error in measuring the load voltage is carried out to adapt to the robust droop method. In practice, when there are errors in the voltage measured, a fundamental tradeoff between the voltage drop and the sharing accuracy appears thus will lead to the errors in proportional load sharing. Unsimilar with the conventional droop control, the author proposed a robust droop controller by implementing $Q-\omega$ and $P-E$ droop analysis and RMS voltage set-points for the inverters through voltage droop. In order to make sure that the voltage remains within a certain required range, the load voltage drop $E^{*}-V_{o}$ needs to be fed back in a certain way, according to the basic principles of control theory. It can be added to $\Delta E_{i}$ via an amplifier, $K_{e}$ and resulted the robust controller as indicated in Figure 3 (a). This control scheme is a benchmarking to the proposed controller in this paper. However, in this paper will be focusing on the frequency regulation; using the frequency droop. Therefore, the frequency droop will be replacing the voltage droop method by modifying the equation of robust droop controller (1). However, the possibility of measured frequency to remain within a certain required range in the parallelconnected inverters usually are quite unmanageable and will conduct in contributing of error value.

$$
V_{r e f}=E \sin (\omega t)
$$

In establishing the parallel-connected inverters enable to share the load, the representation of the conventional droop controller in (2) and (3) are used. The angular frequency, $\omega_{i}$ is widely utilized to generate the frequency of the frequency reference for the inverters, where $\omega^{*}$ is the rated frequency and $m_{i}$ is a droop coefficient. 


$$
\begin{aligned}
& E_{i}=E^{*}-n_{i} P_{i} \\
& \omega_{i}=\omega^{*}+m_{i} Q_{i}
\end{aligned}
$$

From (3), the representation of the frequency droop control can be written as

$$
\Delta \omega_{i}=\omega_{i}-\omega^{*}=m_{i} Q_{i}
$$

and the frequency $\omega_{i}$ can be implemented via integrating $\Delta \omega_{i}$ as

$$
\omega_{i}=\int_{0}^{t} \Delta \omega_{i} d t
$$

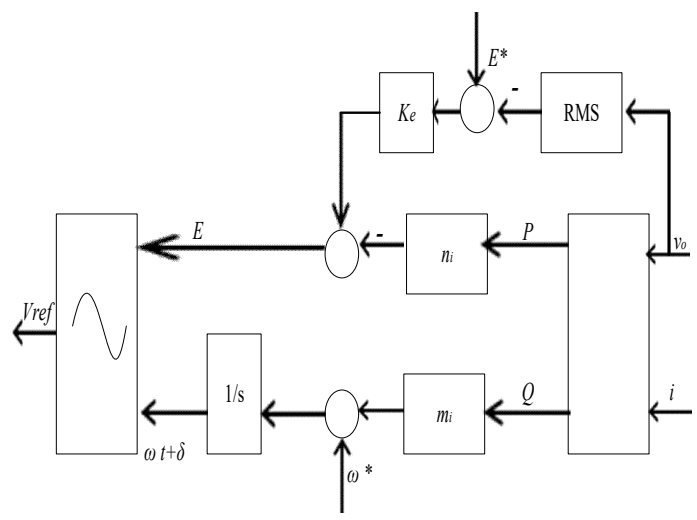

(a)

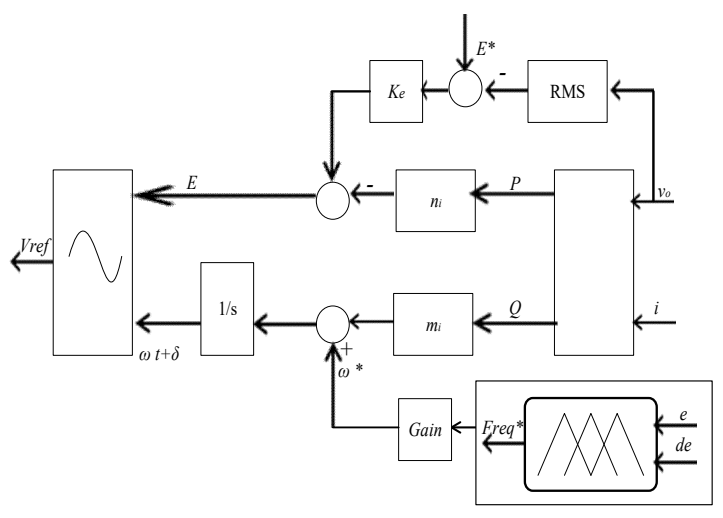

(b)

Figure 3. Control scheme (a) Robust droop (b) Robust droop with FLC

\subsection{FLC-based robust droop control}

In order to improve the as mentioned controller in the previous section, some changes have been made to realize it. Regarding to the proposed controller, the concept and modeling of the basic robust droop controller are already highlighted in [18]. In this paper, FLC method is implemented based on frequency error, $e_{r r}$ of each inverter. The voltage reference, $V_{r e f}$ and new frequency reference (based on the per unit of output voltage) of voltage control unit is brought out by the frequency control unit as indicated in Figure 3 (b). The initiation of the frequency control unit is droop method. Previously, conventional droop control has been used as voltage and frequency regulation and even power sharing process among DG units. In this method, instantaneous active and reactive power components are received from the local measured of current and voltage. Then, they are passed through a low pass filter with cutoff frequency, $\omega_{c}$.

As illustrated in Figure 4, FLC with unity feedback is implemented with robust droop control. The new reference frequency is the output of fuzzy system with respect to two inputs of frequency error $\left(e_{r r}\right)$ and its derivative $\left(d e_{r r} / d t\right)$. The membership function for both input and output are considered to work with triangular membership function. The applied rules are as in Table 1. 


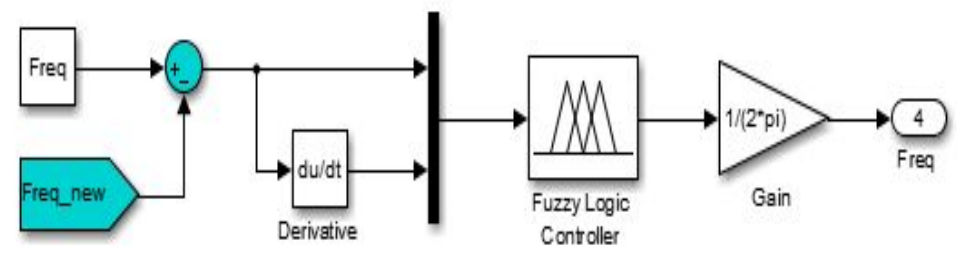

Figure 4. Simulink block of fuzzy logic controller

Table 1. Fuzzy rule base

\begin{tabular}{ccccccc}
\hline \multicolumn{1}{c}{ Derivative of frequency error, $\left(d e_{r r} / d t\right)$} \\
\hline \multirow{4}{*}{ Frequency error, } & NB & NB & NS & ZE & PS & PB \\
$\left(e_{r r}\right)$ & NS & NS & NS & ZE & ZE & NS \\
& ZE & ZE & ZE & ZE & ZE & ZE \\
& PS & ZE & NS & ZE & PS & PS \\
& PB & NS & PS & ZE & PS & PB \\
\hline
\end{tabular}

\section{GENERALIZED MODEL OF SINGLE-PHASE INVERTER}

The model of single-phase inverter used in this work has two inputs, which are input voltage $\left(v_{i}^{*}\right)$ and output current $\left(i_{o}\right)$, and one output, which is the output voltage of the inverter $\left(v_{o}\right)$. $G_{v}$ represents the PR voltage controller of the voltage feedback loop, $K_{f}$ is the gain of the voltage feedforward loop, and $K_{c}$ is the gain of the current feedback loop. In this model, the modulation index of the SPWM modulator is assumed to be 1 , i.e. unity gain. The equation for $G_{v}$ is given in (6).

$$
G_{v}=K_{P}+\frac{K_{\mathrm{Re} s}(s+\omega)}{s^{2}+2 \omega_{c} s+\omega_{c}^{2}+\omega_{o}^{2}}
$$

The proportional gain, resonant gain, and cutoff frequency of the PR controller is represented by $K_{P}$ , $K_{\text {Res }}$, and $w_{c}$ respectively, and $w_{o}$ is the fundamental frequency of the system. The closed-loop voltage gain, $G$ can be derived from Figure 5 using the reduction block method. By setting $i_{o}$ to be 0 , and the model can be simplified to (7). By setting $v_{i}^{*}$ to 0 , the model can be simplified to (8) to find the output impedance of the inverter

$$
\begin{aligned}
& G=\frac{K_{i}\left(G_{v}+K_{f}\right)}{C_{f} L_{f} s^{2}+\left(C_{f} R_{f}+C_{f} K_{c}\right) s+K_{i} G_{v}+1} \\
& Z=\frac{L_{f} s+R_{f}}{L_{f} C_{f} s^{2}+\left(R_{f} C_{f}+K_{i} K_{c} C_{f}\right) s+K_{i} G_{v}+1}
\end{aligned}
$$

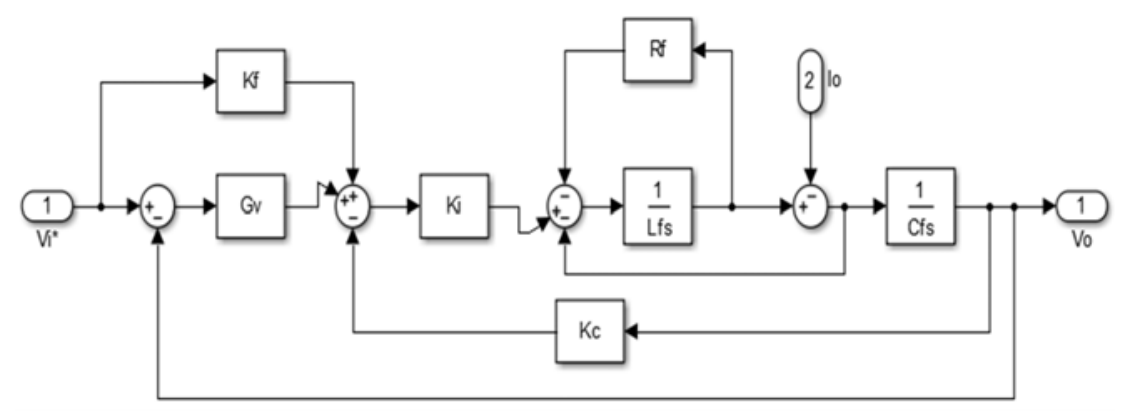

Figure 5. Inverter model with instantaneous current sharing scheme 


\section{SIMULATION RESULTS AND ANALYSIS}

In this section, several MATLAB/SIMULINK simulations have been taken to investigate the performance of both controllers' schemes. Both of the methods are using the frequency droop so that both of the results from both controllers can be examined in the same analysis. The analysis is based on the frequency reference that capable in generating the output of voltage and current as well as the equality of load power sharing when a load disturbance occurs in the parallel-connected inverters. System parameters used are as shown in Table 2.

Table 2. Parameter list

\begin{tabular}{cc}
\hline Description & Value \\
\hline Filter Inductance & $1 \mathrm{mH}$ \\
Filter Resistance & $5 \Omega$ \\
Filter Capacitance & $20 \mu \mathrm{F}$ \\
Capacitor Current Gain $\left(K_{c}\right)$ & 10 \\
Nominal Frequency $\left(w_{\mathrm{o}}\right)$ & $314.15 \mathrm{rad} / \mathrm{s}$ \\
Cutoff Frequency $\left(w_{\mathrm{c}}\right)$ & $10 \mathrm{~Hz}$ \\
Number of Parallel Connected Inverter $(n)$ & 3 \\
Amplifier $\left(K_{e}\right)$ & 3 \\
$D C$ Link Voltage $\left(V_{D C}\right)$ & $400 \mathrm{~V}$ \\
Number of load Impedance $\left(Z_{L}\right)$ & 2 \\
Line Resistance & $3.42 \mathrm{e}^{-3} \Omega$ \\
Line Inductance & $2.73 \mu \mathrm{F}$ \\
\hline
\end{tabular}

The simulation results obtained is done using the line impedance values as shown in Table 2 . The function of breaker is applied in the simulation to make it easier to plug in and disconnect the inverters and the loads. The inverters configuration and load condition are similar in both control methods.

As depicted in Figure 6 (a), the proposed controller is able to remain at the rated frequency of $50 \mathrm{~Hz}$ after load change at $1.7 \mathrm{~s}$. However, the frequency of the robust droop becomes unstable after load change at $1.7 \mathrm{~s}$ and it has remained oscillating more than $50 \mathrm{~Hz}$ as required. The result of the frequency deviation of both controllers is shown in Figure 6 (b), indicates the proposed controller is able in reducing the error when the load change happens.

The correlation result of analysis of the output voltage of both systems is presented in Figure 7 (a). From the figure, it can be observed that the voltage of the robust droop controller becomes unstable starting at $t=1.4 \mathrm{~s}$, while all the inverters and loads are disconnected from line impedance. In Figure 7 (b) shows the output current of both methods. Likewise, the output voltage, the result without FLC shows the instability of the response especially at $t=1.4 \mathrm{~s}$, the current still circulate in the line even though all the inverters and loads are disconnected from line impedance.

As shown in Figure 8 and Figure 9, there was a significant difference between both controllers. It can be seen that the response of the inverters using previous robust droop technique is unstable, especially at $t=0.8 \mathrm{~s}$, the result of the reactive power of inverter 3 took $0.18 \mathrm{~s}$ to reach the steady-state if compared to $0.03 \mathrm{~s}$ taken by the proposed technique to achieve the steady-state condition. Furthermore, the average of transient response of the active power in Figure 8 is obtained using the proposed controller better than the response by using the robust droop controller.

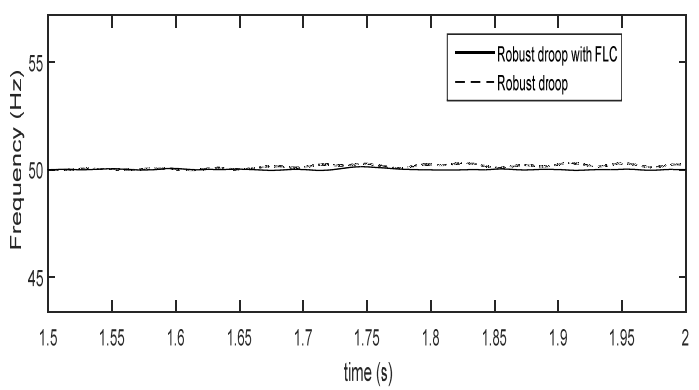

(a)

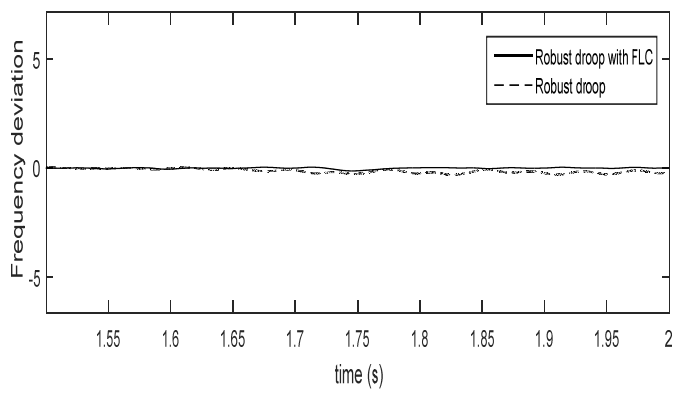

(b)

Figure 6. Simulation results of (a) Load frequency of both controllers to achieve steady-state at $50 \mathrm{~Hz}$ (b) Frequency deviation of both controllers 


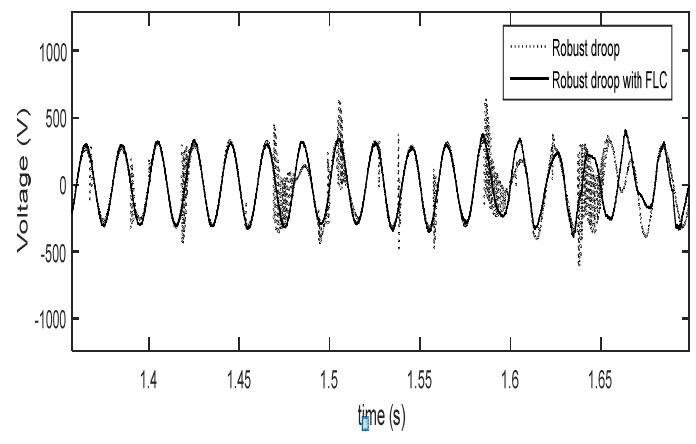

(a)

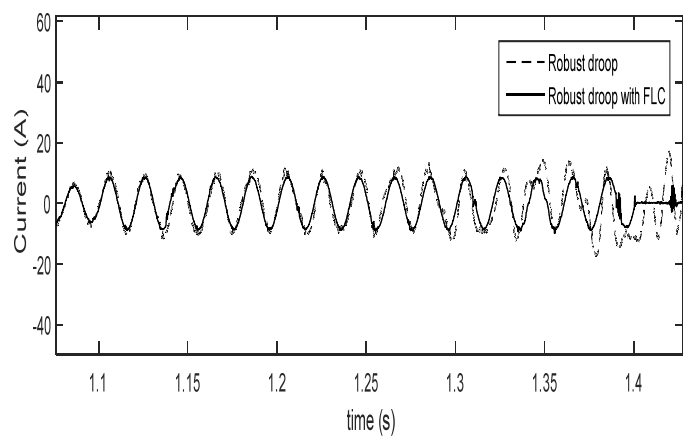

(b)

Figure 7. Simulation results of output currents of three parallel-connected inverters and load (a) with proposed technique (b) with previous robust droop technique

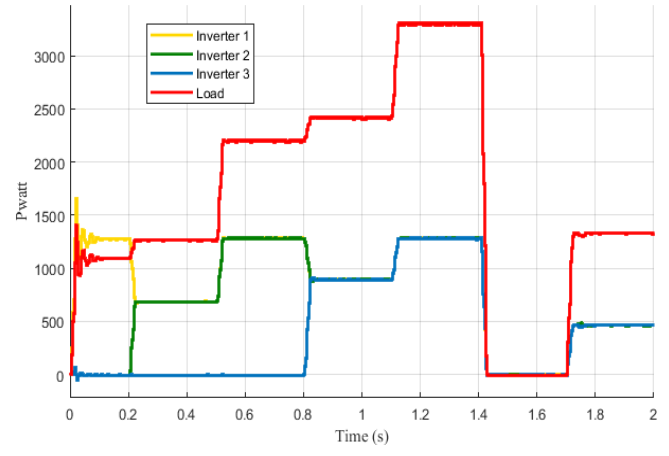

(a)

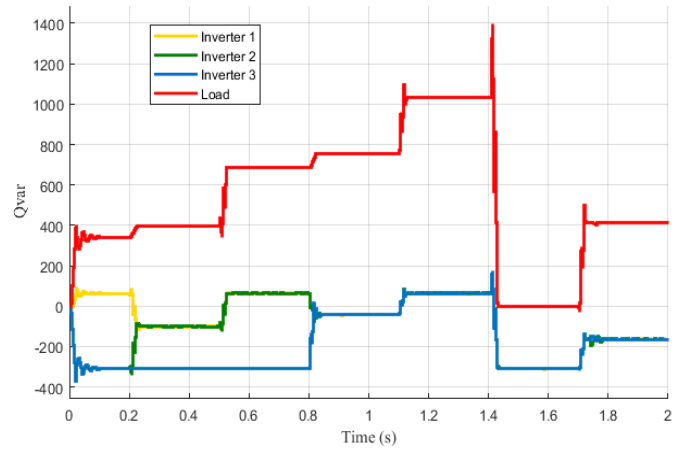

(b)

Figure 8. Simulation results of output power of three parallel-connected inverters and load with proposed technique (a) active power, $\mathrm{P}(\mathrm{b})$ reactive power, $\mathrm{Q}$

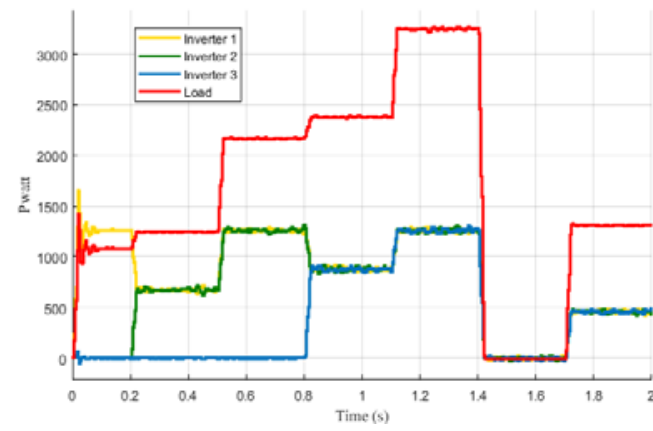

(a)

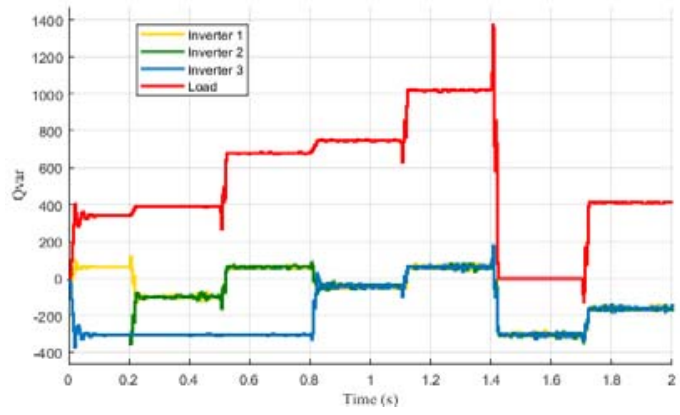

(b)

Figure 9. Simulation results of output power of three parallel-connected inverters and load with previous robust droop technique (a) active power, $\mathrm{P}(\mathrm{b})$ reactive power, $\mathrm{Q}$

\section{CONCLUSION}

This paper has presented a modified robust droop controller using FLC in parallel-connected inverters. It focused on control action taken in remaining the frequency reference by applying the frequency 
droop method. A simplified model of single-phase inverter is used to investigate system stability in terms of output current and voltage. The rules of FLC are tuned to deal with the error and change of error of frequency of the system. According to the results above, the proposed control strategy is able to provide a stable angular frequency for microgrids working in the islanded mode. The limited scope of the previous robust droop controller that analyzed with voltage droop has been noticed. Meanwhile, the proposed controller has proven that it is capable of outperforming the lacks of the robust droop controller in providing a smooth and stable in line response. Additionally, with less overshoot in response and dependable in a line perturbation show that the proposed controller achieves good performance in system response with less circulating current as well as better power sharing.

\section{REFERENCES}

[1] A. W. N. Husna, S. F. Siraj, and M. Z. Ab Muin, "Modeling of DC-DC converter for solar energy system applications," in 2012 IEEE Symposium on Computers and Informatics, ISCI 2012, 2012.

[2] T. Hornik and Q.-C. Zhong, "A Current-Control Strategy for Voltage-Source Inverters in Microgrids Based on $\$ \mathrm{H}^{\wedge}\{$ \infty \}\$ and Repetitive Control,” IEEE Trans. Power Electron., vol. 26, no. 3, pp. 943-952, Mar. 2011.

[3] P. Tenti, H. K. M. Paredes, and P. Mattavelli, "Conservative Power Theory, a Framework to Approach Control and Accountability Issues in Smart Microgrids," IEEE Trans. Power Electron., vol. 26, no. 3, pp. 664-673, Mar. 2011.

[4] J. Rocabert, G. M. S. Azevedo, A. Luna, J. M. Guerrero, J. I. Candela, and P. Rodríguez, "Intelligent Connection Agent for Three-Phase Grid-Connected Microgrids," IEEE Trans. Power Electron., vol. 26, no. 10, pp. 2993-3005, Oct. 2011.

[5] P. Ji, X. X. Zhou, and S. Wu, "Review on sustainable development of island microgrid," in 2011 International Conference on Advanced Power System Automation and Protection, 2011, pp. 1806-1813.

[6] M. S. Sadabadi, Q. Shafiee, and A. Karimi, "Plug-and-Play Voltage Stabilization in Inverter-Interfaced Microgrids via a Robust Control Strategy," IEEE Trans. Control Syst. Technol., vol. 25, no. 3, pp. 781-791, May 2017.

[7] A. W. N. Husna, S. F. Siraj, and M. H. Mat, "Effect of load variations in DC-DC converter," in Proceedings CIMSim 2011: 3rd International Conference on Computational Intelligence, Modelling and Simulation, 2011.

[8] N. Bottrell, M. Prodanovic, and T. C. Green, "Dynamic Stability of a Microgrid With an Active Load," IEEE Trans. Power Electron., vol. 28, no. 11, pp. 5107-5119, Nov. 2013.

[9] M. A. Roslan, M. S. Ahmad, M. A. M. Isa, and N. H. A. Rahman, "Circulating current in parallel connected inverter system," in 2016 IEEE International Conference on Power and Energy (PECon), 2016, pp. 172-177.

[10] A. Vijayakumari, A. T. Devarajan, and N. Devarajan, "Decoupled control of grid connected inverter with dynamic online grid impedance measurements for micro grid applications," Int. J. Electr. Power Energy Syst., vol. 68, pp. 1-14, Jun. 2015.

[11] M. R. Miveh, M. F. Rahmat, A. A. Ghadimi, and M. W. Mustafa, "Control techniques for three-phase four-leg voltage source inverters in autonomous microgrids: A review," Renew. Sustain. Energy Rev., vol. 54, pp. 1592-1610, 2016.

[12] N. H. A. Wahab, M. H. Mat, and M. A. Roslan, "A Review on Optimization of Control Strategy on Paralleled Connected Inverters in an Islanded Microgrid," Adv. Sci. Lett., vol. 23, no. 6, pp. 5406-5409, Jun. 2017.

[13] P. Monica, M. Kowsalya, and P. C. Tejaswi, "Load sharing control of parallel operated single phase inverters," Energy Procedia, vol. 117, pp. 600-606, 2017.

[14] P. Sreekumar and V. Khadkikar, "Nonlinear load sharing in low voltage microgrid using negative virtual harmonic impedance," IECON 2015 - 41st Annu. Conf. IEEE Ind. Electron. Soc., no. 1, pp. 3353-3358, 2015.

[15] Institute of Electrical and Electronics Engineers. and IEEE-SA Standards Board., IEEE guide for design, operation, and integration of distributed resource island systems with electric power systems. Institute of Electrical and Electronics Engineers, 2011.

[16] Y. Mohamed and E. F. El-Saadany, "Adaptive Decentralized Droop Controller to Preserve Power Sharing Stability of Paralleled Inverters in Distributed Generation Microgrids," IEEE Trans. Power Electron., vol. 23, no. 6, pp. 2806-2816, Nov. 2008.

[17] A. M. Bouzid, J. M. Guerrero, A. Cheriti, M. Bouhamida, P. Sicard, and M. Benghanem, "A survey on control of electric power distributed generation systems for microgrid applications," Renew. Sustain. Energy Rev., vol. 44, pp. 751-766, 2015.

[18] Q. C. Zhong, "Robust droop controller for accurate proportional load sharing among inverters operated in parallel," IEEE Trans. Ind. Electron., vol. 60, no. 4, pp. 1281-1290, 2013.

[19] A. Hasanzadeh, O. C. Onar, H. Mokhtari, and A. Khaligh, "A Proportional-Resonant Controller-Based Wireless Control Strategy With a Reduced Number of Sensors for Parallel-Operated UPSs," IEEE Trans. Power Deliv., vol. 25, no. 1, pp. 468-478, Jan. 2010. 